\title{
Nonlinear Compensation Empyoing Matrix Converter with
} DTC Controller

\author{
Khalaf S. Gaied ${ }^{1}$, Ziad H. Salih', Ahmed R. Ajel ${ }^{3}$, Mehdi J. Marie \\ ${ }^{1}$ College of Engineering, Tikrit University, Iraq \\ ${ }^{2}$ College of Petroleom and Mineral Engineering, Tikrit University, Iraq \\ ${ }^{3}$ Institute of Technology, Baghdad, Iraq \\ ${ }^{4} \mathrm{Al}$-Zawraa state company, Ministry of Industry, Iraq
}

\section{Article Info \\ Article history: \\ Received Sep 10, 2016 \\ Revised Jan 7, 2016 \\ Accepted Jan 21, 2017}

\section{Keyword:}

Direct torque control

Fault diagnosis

Matrix converter

Nonlinear compensation

Space vector modulation

\begin{abstract}
This paper describes a nonlinear harmful speed and torque controller for fourth order induction motor model. The investigation of optimality and cost function for that base on estimation of Hammerstein-Wiener model with the compensated mathematical model. The matrix converter with direct torque control combination is efficient way to get better performance specifications in the industry. The MC and the DTC advantages are combined together.The reduction of complexity and cost of DC link in the DTC since it has no capacitors in the circuit. However, the controlling torque is a big problem it in DTC because of high ripple torque production which results in vibrations response in the operation of the IM as it has no PID to control the torque directly. The combination of MC with DTC is applied to reduce the fluctuation in the output torque and minimize the steady state error. This paper presents the simulation analysis of induction machine drives using Maltlab/Simulink toolbox R2012a. Design of constant switching frequency MCDTC drive,stability investigation and fault protection as well as controllability and observability with minimum steady state error has been carried out which proved the effectiveness of the proposed technique.
\end{abstract}

Copyright $@ 2017$ Institute of Advanced Engineering and Science. All rights reserved.

\section{Corresponding Author:}

Khalaf S. Gaied,

Electrical Engineering Department, Tirit University,

Tikrit state, +9647703057076, Iraq.

Email: gaeidkhalaf@gmail.com, salim_hazim2000@siswa.um.edu.my

\section{NOMENCLATURES}

$\begin{array}{llll}A D R C & \text { Auto Disturbance Rejection Controller } & \text { Ls } & \text { Stator Inductance } \\ A S D & \text { Adjustable Speed Drive } & L r & \text { Rotor Inductance } \\ D T C & \text { Direct Torque Control } & \text { Lm } & \text { Mutual Inductance } \\ D T C I M & \text { Direct Torque Control Induction Motor } & i s & \text { Stator Current } \\ D S C & \text { Direct Self Control } & i r & \text { Rotor Current } \\ F P E & \text { Final Predicted Error } & v s & \text { Stator Voltage } \\ M C & \text { Matrix Converter } & e s & \text { Electromotive Force Vector } \\ \text { MCDTC } & \text { Matrix Converter with Direct Torque Control } & t s p & \text { Sampling Period } \\ I M & \text { Induction Motor } & V_{o p} & \text { Output Voltage Vector } \\ P I & \text { Proportional Integral } & V i p & \text { Input Voltage Vector. } \\ R r & \text { Rotor Resistance } & & \end{array}$




\section{INTRODUCTION}

In industry life all systems are nonlinear, to make the investigation(analysis and design), most of these systems considered as linear. DTC and control of non-linear levels in the systems are considered the most important techniques for achieving high performance in AC machines [1]. The induction motors (IM) plays an important role. in the industry due to their low cost and operational reliability [2]. Adjustable speed drives (ASDs) are frequently used in many applications, such as air conditioning, elevators, electrical vehicles, ventilation, pumps, fans, heating, robotics [3]. In 1984, I. Takahashi developed a new technique for the torque control of IM which is one kind of variable speed drives named as Direct Torque Control (DTC) [4]. The principle is emulate both flux and torque as in the DC machines by the orientation control of the magnetic field. The DTC configuration for direct MC has been presented in [5]. In a DTCIM drive, a decoupled control of torque and flux can be achieved by two independent control loops [6].

This configuration play vital role in the industry due many reasons like ability to adjust input power factor, no need to DC link capacitor, ensure sinusoidal waveforms for the input and output and power flow control in the forward and backward directions. Comprehensive researches studies on direct MC with DTC [7]. The available literature on DTC drives too are mainly confined to performance enhancement in terms of torque ripples. Since the steady state as well as dynamic performance of a DTC drive is greatly affected by the flux control loop which in turn depends upon flux estimation algorithm [8]. Nonlinear robust controller for MC fed IMD in which a nonlinear robust ADRC is applied to the MC fed IM drive system, taking the place of PI controller [9]. Fuzzy logic controller of multilevel inverter, the SVM presented in [10]. In [11] the inverter voltage vector selected from the switching table is applied for the time interval needed by the torque to reach the upper limit or lower limit of the band, where the time interval is calculated from a suitable modelling of the torque dynamics. AC-DC-AC sparse direct power converter introduced in [12]. Control of a two stage direct power converter with a single voltage sensor mounted in the intermediary circuit presented in [13]. The DTC can be divided into two types, either DSC or SVM. DTCSVM for IM driven by MC using a parameter estimation strategy done by [14]. The switching table has many drawbacks such as variable switching frequency due to hysteresis bands of both torque and flux as well as the change of speed motor. According to this variation in switching frequency, uncontrolled small region will be generated especially in the beginning of operation of induction motor. The main drawbacks of the DTC system are the variable inverter switching frequency and high torque output ripple due to usage of hysteresis based comparators to control the output torque [15]. To obtain good solution for that, SVM with DTC and MC has been used. The stability is one of the most important demands in the control system after being subjected to a disturbance [16]. The MC can be used in the compressors, fans (blowers), mixers, general pumps or heat pumps and escalator drive system [17]. In this paper, a combination of fixed switching frequency DTC with MC scheme is presented, which developed to minimize the steady state error of input torque due highly torque noise in the DTC scheme that should be suppressed.

\section{DTC BACKGROUND}

DTC can achieve field orientation without feedback, using motor theory to calculate the motor torque. It is said to use the fastest digital signal processing hard-ware available and a more advanced mathematical understanding of how motors work [18].

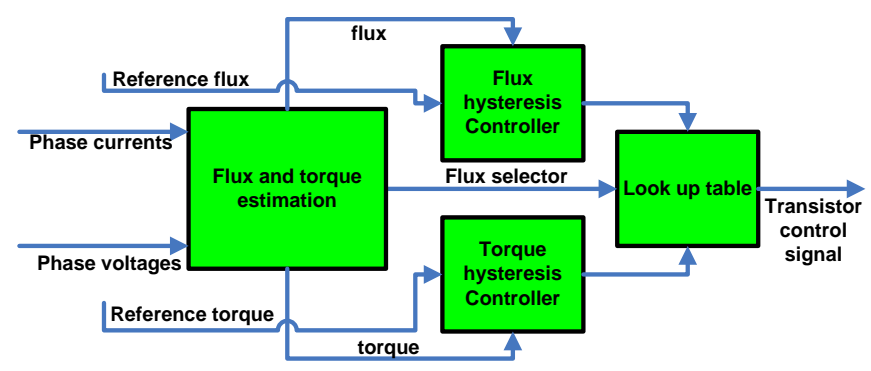

Figure 1. Principle of the DTC

The DTC technique principle is shown in the Figure 1 can be illustrated as follow: At the first step, the phase currents and voltages of the system are measured. The outcome of forwarding such values to the 
flux and torque estimator will be the actual flux and torque of the system. The estimated torque is com-pared with their reference values in three levels torque hysteresis controller. At same time, the flux is compared with the reference flux values in two levels flux hysteresis controller. In order to construct the transistor control signal, the outputs of the stator flux and torque controllers further to the flux selector are used as inputs of the DTC switching look up table.

The transistors control signals which are divided into nine different sections are used for controlling the three levels MC, as can be shown in the Figure 2.

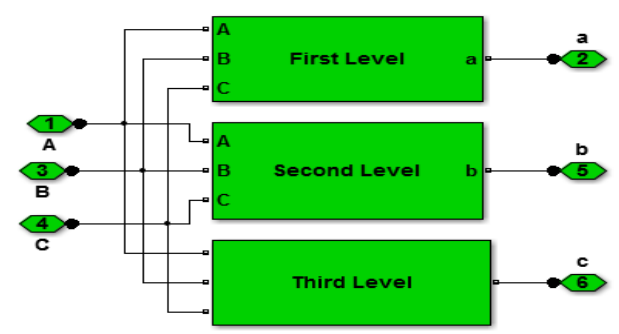

Figure 2. Simulink Implementation of the Three Levels MC [19]

The internal connection of each level shown above will as in Figure 3.

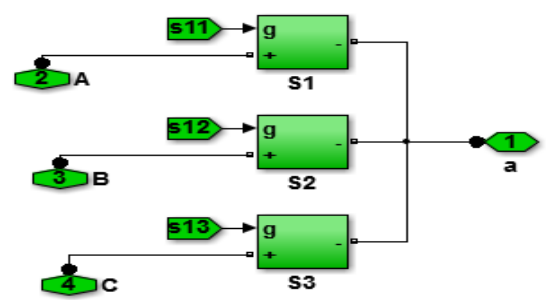

Figure 3. Simulink Implementation of the First Level

The details information of each block shown in Figure 3 will be as in Figure 4.

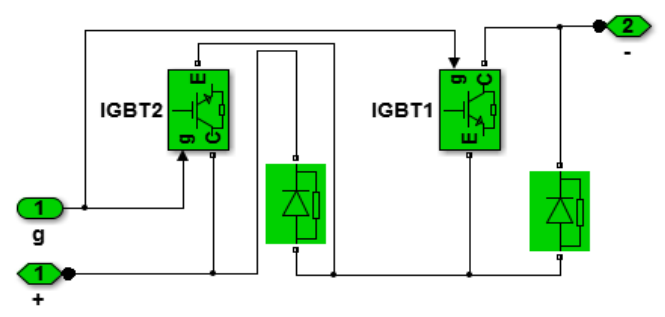

Figure 4. Details Connection of each Block shown in Figure 3 Table 1.

The general selection table for the DTC, being $(\mathrm{k})$ which is the sector number can be shown in

Table 1. General Selection Table

\begin{tabular}{cccc}
\hline & $\Psi_{\mathrm{s}}$ sector $\mathrm{K}$ & \multicolumn{3}{c}{ Torque } \\
\hline \multirow{4}{*}{ Flux } & & Increase & Decrease \\
& Increase & $\mathrm{V}_{\mathrm{k}+1}$ & $\mathrm{~V}_{000}$ \\
& Decrease & $\mathrm{V}_{\mathrm{k}+2}$ & $\mathrm{~V}_{111}$ \\
\hline
\end{tabular}


DTC zero sequence $\left(\mathrm{V}_{000}\right.$ or $\left.\mathrm{V}_{111}\right)$ vectors are used to maintain the torque constant and not including during the switching period.The switching table in DTC allows selecting the vector position to apply to the MC according to the DC of the stator flux and the electromagnetic torque as can be shown in Table 2. From Table 1, one can notice that the switching frequency of the IGBTs used in this scheme is not constant. If we control the tolerance bands, the average switching frequency can be kept at its reference value, hence the ripple current and torque will be minimized [20].

Table 2. DTC switching Table

\begin{tabular}{cccccccc}
\hline & & \multicolumn{7}{c}{ Sector } \\
& & 1 & 2 & 3 & 4 & 5 & 6 \\
\hline \multirow{3}{*}{$\mathrm{d} \varphi=+1$} & $\mathrm{dT}=+1$ & $\mathrm{~V}_{2}$ & $\mathrm{~V}_{3}$ & $\mathrm{~V}_{4}$ & $\mathrm{~V}_{5}$ & $\mathrm{~V}_{6}$ & $\mathrm{~V}_{1}$ \\
& $\mathrm{dT}=0$ & $\mathrm{~V}_{0}$ & $\mathrm{~V}_{7}$ & $\mathrm{~V}_{0}$ & $\mathrm{~V}_{7}$ & $\mathrm{~V}_{0}$ & $\mathrm{~V}_{7}$ \\
& $\mathrm{dT}=-1$ & $\mathrm{~V}_{6}$ & $\mathrm{~V}_{1}$ & $\mathrm{~V}_{2}$ & $\mathrm{~V}_{3}$ & $\mathrm{~V}_{4}$ & $\mathrm{~V}_{5}$ \\
$\mathrm{~d} \varphi=-1$ & $\mathrm{dT}=+1$ & $\mathrm{~V}_{3}$ & $\mathrm{~V}_{4}$ & $\mathrm{~V}_{5}$ & $\mathrm{~V}_{6}$ & $\mathrm{~V}_{1}$ & $\mathrm{~V}_{2}$ \\
& $\mathrm{dT}=0$ & $\mathrm{~V}_{7}$ & $\mathrm{~V}_{0}$ & $\mathrm{~V}_{7}$ & $\mathrm{~V}_{0}$ & $\mathrm{~V}_{7}$ & $\mathrm{~V}_{0}$ \\
& $\mathrm{dT}=-1$ & $\mathrm{~V}_{5}$ & $\mathrm{~V}_{6}$ & $\mathrm{~V}_{1}$ & $\mathrm{~V}_{2}$ & $\mathrm{~V}_{3}$ & $\mathrm{~V}_{4}$ \\
\hline
\end{tabular}

The MCDTC proposed algorithm can be shown in Figure 5.

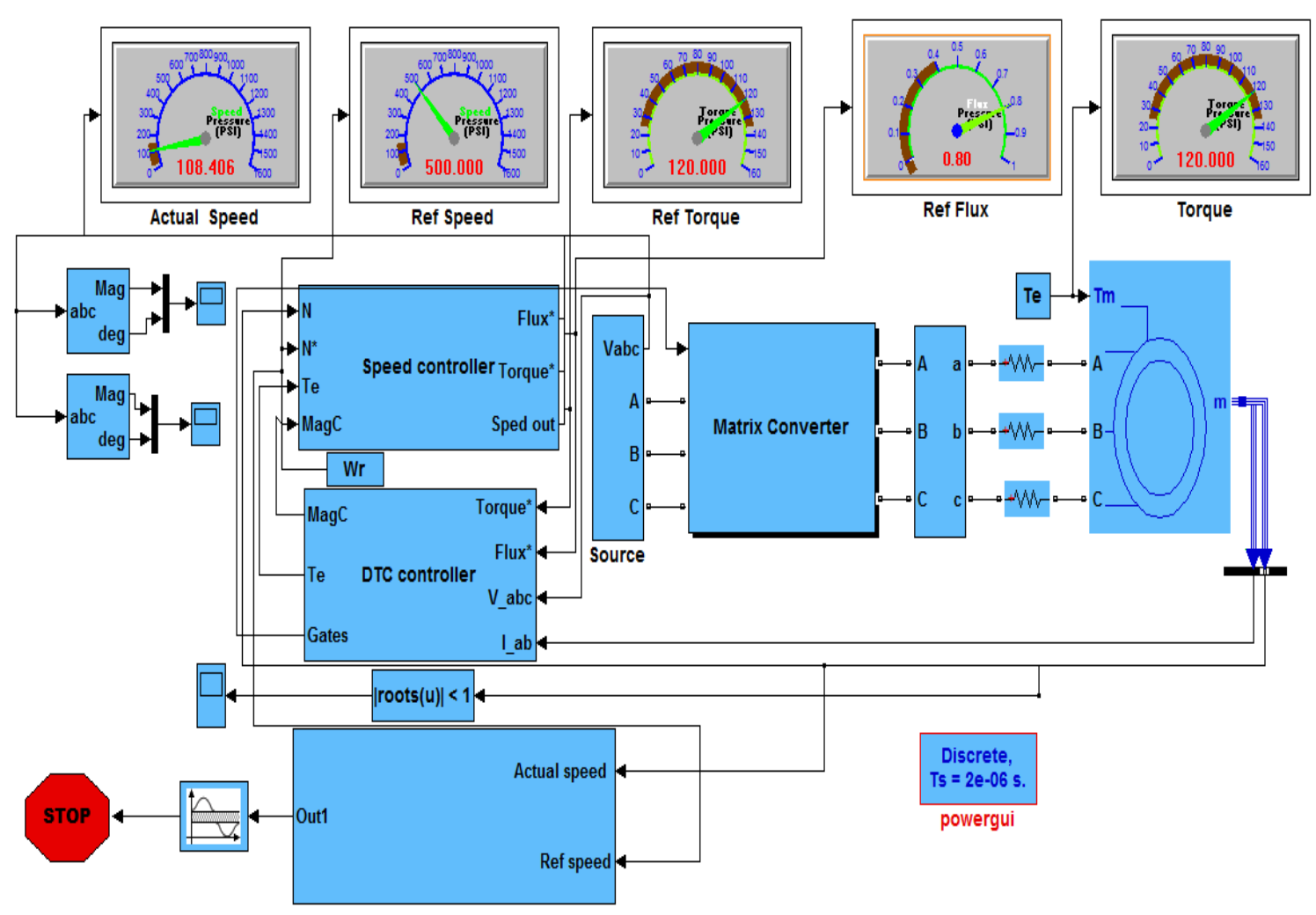

Figure 5. The Proposed Fixed Frequency DTC Scheme using MC

\section{MATRIX CONVERTER}

A device which converts AC input supply to the required variable AC supply as output without any intermediate conversion process whereas in case of Inverter which converts AC - DC - AC which takes more extra components as diode rectifiers, filters, charge-up circuit but not needed those in case of MC [21] device which converts $\mathrm{AC}$ input supply to the required variable $\mathrm{AC}$ supply as output without any intermediate conversion process whereas in case of Inverter which converts AC - DC - AC which takes more extra components as diode rectifiers, filters, charge-up circuit but not needed those in case of MC. The Eupec Economac matrix module with nine back-to-back IGBT switches can be seen in Figure 6. 


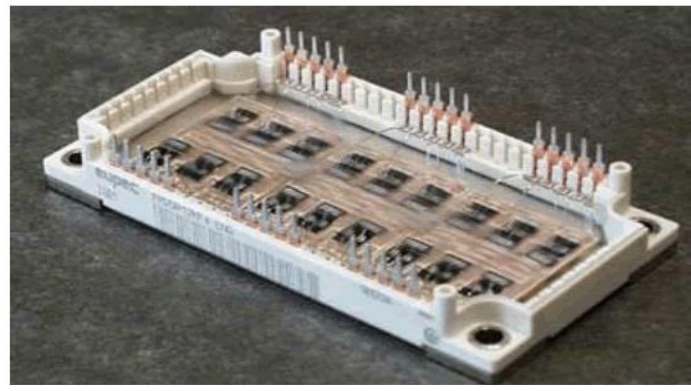

Figure 6. The Eupec Economac Matrix Module

The advantages of the MC compared to conventional inverter types are as follows:

a. Waveforms of both Input and output are very clear [22-23]

b. Minimal higher order harmonics are obtained

c. Capability of sub harmonics omitting

d. Capability of bi-directional energy flow

e. It has no DC link capacitors

f. Control of input power factor can be performed easily

The disadvantages of the MC are as follows:

a. Maximum efficiency cannot be obtained in all cases

b. The conventional AC-AC has fewer components compared to the MC

c. Each bi-directional switch should have its arrangement

d. Sensitive to input voltage system

e. No monolithic bi-directional switches exist

The system consists of a 3-phase MC constructed from 9 back-to-back IGBT switches. The MC is supplied with three phase source and drives a static resistive load. The switching algorithm is based on SVM described earlier which considers the MC as a rectifier and inverter connected via a DC link with no energy storage. Indirect SVM allows direct control of input current and output voltage and hence allows the power factor of the source to be controlled. The switching algorithm utilizes a symmetric switching sequence mentioned before. First of all the Simulink implementation of the MC is carried out. MC consists of nine bidirectional sectors with reverse blocking capability, arranged as three sets of three so that any of the three input phases can be connected to any of the three output lines. A bi-directional 18 diodes is used for blocking the voltage in MC [24]. The inversion matrix sequence of the SVM when the voltage mod input to generate (v1-v2-v7-v8) with the switching pattern is constructed as in the Figure 7.

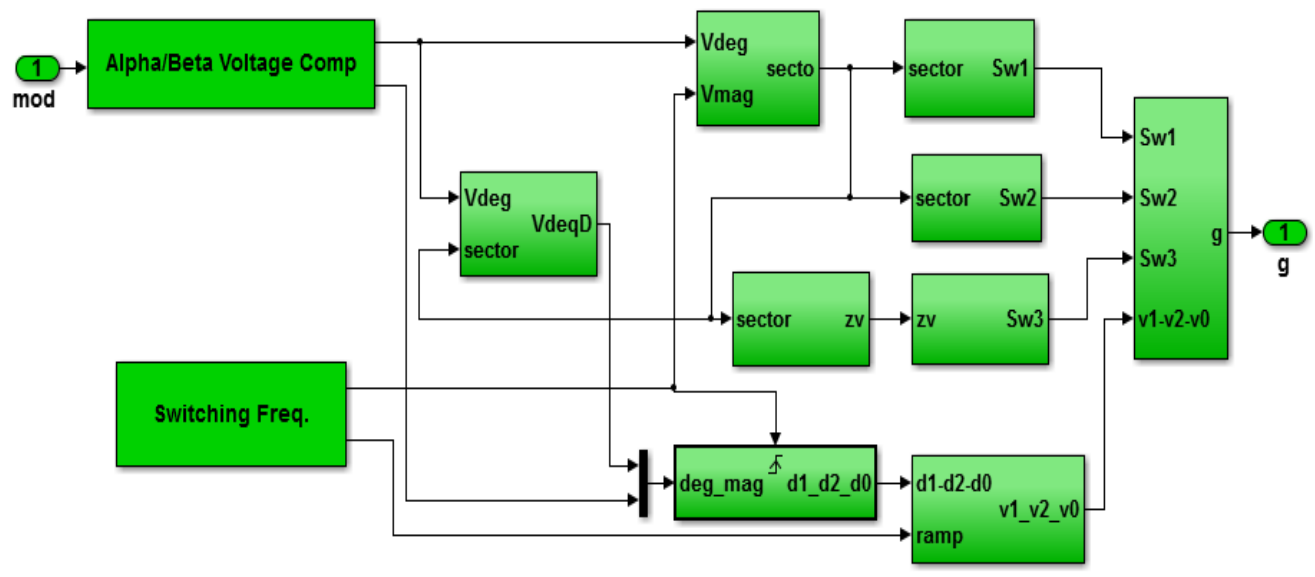

Figure 7. MCSVM Symmetric Switching in the Voltage Mod Input

In the first position (0-60) degree, the torque will be decreased while the flux will be increased. In the positions $(60-120)$ or $(-120-(-60))$ there is a flux ambiguity, in the position $(-180-(-120))$ the torque and 
the flux will be decreased and last position (180-120) the torque will be increase while the flux will be increased. There are two position between(30-(-30)) are not used because the torque will increased or decreased in the same sector depending on the position if it's in the position of 30 or $(-30)$.

The symmetric sequence unit used the current mod as the input to generate (v1-v2-v0) also used. SVM symmetric sequence unit for generation of v1_v2_v7_v8 sequence can be implemented using Matlab/Simulink as in Figure 8.

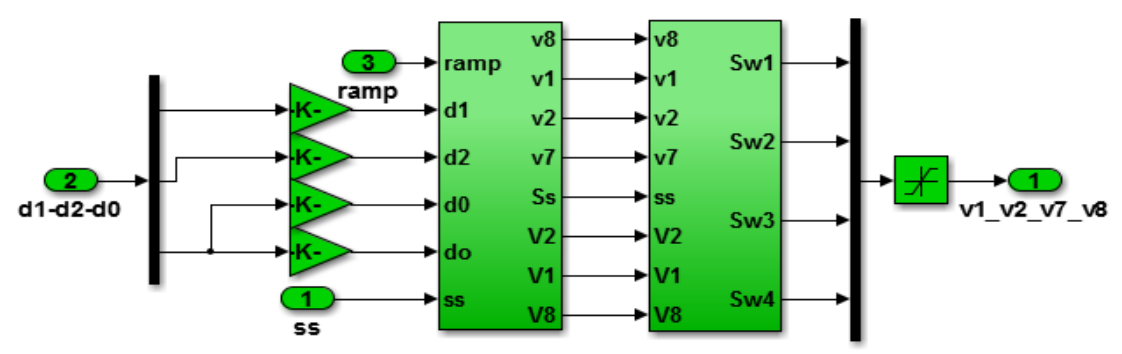

Figure 8. SVM Symmetric Sequence Unit of the above Figure

An IM can be described in the stationary frame by the following flux and voltage equations.

$$
\begin{aligned}
& \psi_{s}=L_{s} i_{s}+L_{m} i_{r} \\
& \psi_{r}=L_{m} i_{s}+L_{m} i_{r} \\
& v_{s}=R_{s} i_{s}+\frac{d \psi_{s}}{d t} \\
& 0=R_{r} i_{r}+\frac{d \psi_{r}}{d t}-j \omega_{r} \psi_{r}
\end{aligned}
$$

The stator flux variation can be expressed as:

$$
\Delta \psi_{s}=\left(v_{s}-R_{s} i_{s}\right) t_{s p}=e_{s} t_{s p} \cong v_{s} t_{s p}
$$

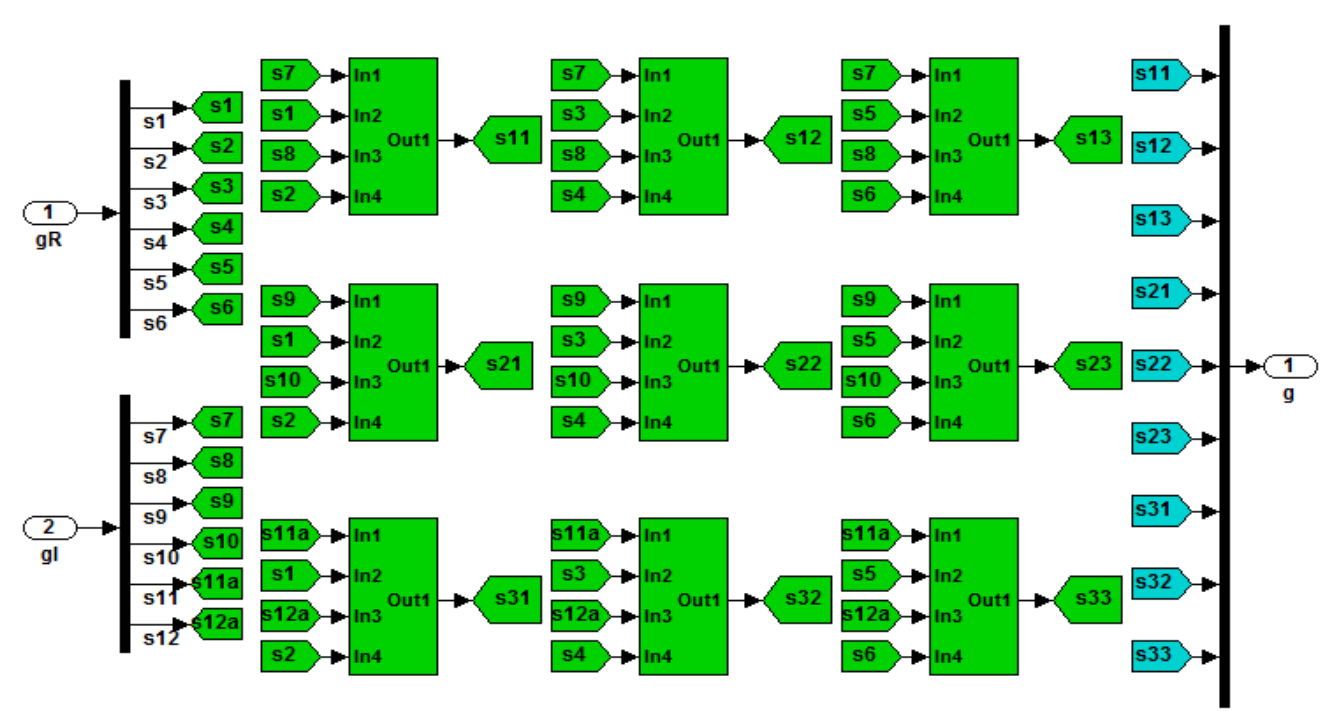

Figure 9. Switching Signal Construction 
To generate the control signal, the MC gates can be constructed from two lookup tables. First one when the magnitude of the flux equal one and the other one when the flux is equal to minus one.

The combinations from 1 to 9 which are the sectors (v0-v1-v2-v3-v4-v5-v6-v7-v8) are used as a gate signal of the IGBT transistor as can be shown in the Figure 9.

The first 6 states can be constructed from the current mode (qR) and the other 6 state as constructed from the voltage mode circuit (ql). The combinations of these 12 signals are used to construct the SVM used to control the MC. Where in $\mathrm{g}$ is the output angle in the SVM rectification system to generate left ( $\mathrm{gl}$ ) and right $(\mathrm{gR})$ axis of the sector when the voltage and current mode acts as the inputs to the circuits.

\section{MC SWITHING SEQUENCE}

The MC can be used as one of the following.

1. MC applicable as a cyclo-converter.

2. MC applicable as a cyclo inverter.

3. MC applicable as a Dual Converter, rectifier and inverter [25]

The control requirement of the switches of MC through the duty cycle depends on the average output voltages to construct the required sinusoidal frequency and magnitude of the three phase voltage [26]. The MC switching generation signal combination with the SVM rectification sequence can be shown in Figure 10 .

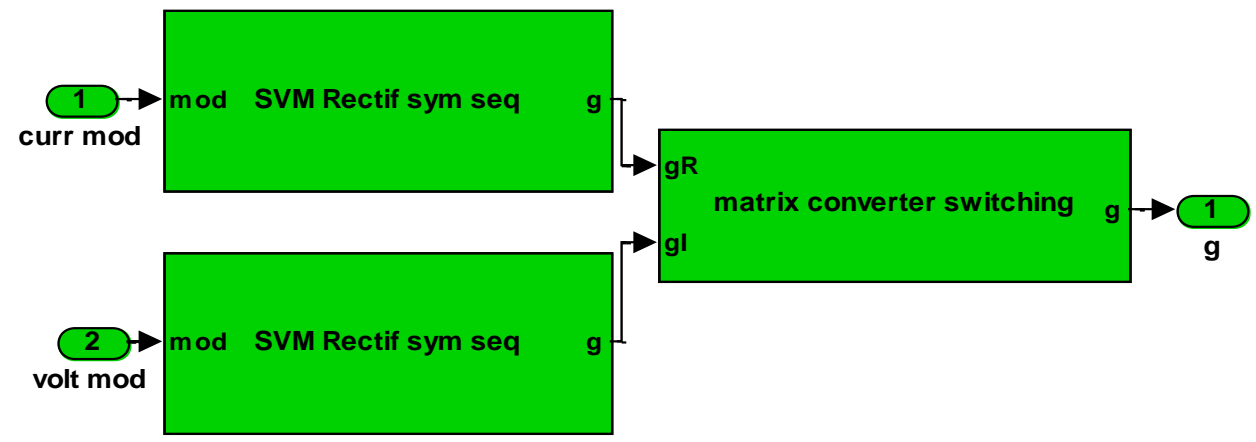

Figure 10. MC switching Generation Signal

The reduction of harmonics in the input power supply can be obtained by MC compared with conventional inverter as well as there is cost reduction [27].

The SVM modulation of the proposed algorithm, required to measure any line voltages. Then, Vi/p and $\varphi \mathrm{i} / \mathrm{p}$ are calculated as:

$$
\begin{gathered}
V_{i / p}^{2}=4 / 9\left(V_{a b}^{2}+V_{b c}^{2}+V_{a b} V_{b c}\right) \\
\varphi_{i / p}=\tan ^{-1}\left(\frac{-V_{b c}}{\sqrt{3}\left(2 / 3 V_{a b}+1 / 3 V_{b c}\right.}\right)
\end{gathered}
$$

The ratio between input and the output voltages is calculated as

$$
R_{v}=\sqrt{\frac{V_{o / p}^{2}}{V^{2}{ }_{i / p}}}
$$

The switching function of any IGBT switch can be expressed as in [28]. Where $K=\{A, B, C\}$ is labelled input phase and $\mathrm{j}=\{\mathrm{a}, \mathrm{b}, \mathrm{c}\}$ is labelled the output phase. The condition of the switching function can be expressed by the following relationship:

$$
S_{A J}+S_{B J}+S_{C J}=1
$$


Under these constrains, a $3 \times 3 \mathrm{MC}$ has been implemented with 27 possible switching states. Let $\mathrm{dKj}(\mathrm{t})$ be the duty cycle of switch $\mathrm{SKj}$, defined as:

$$
d_{K J}(t)=t_{K J} / t_{\text {sampling }} \& 0<d_{K J}<1
$$

The low frequency of MC can be obtained by:

$$
D(t)=\left[\begin{array}{lll}
d_{A a}(t) & d_{B a}(t) & d_{C a}(t) \\
d_{A b}(t) & d_{B b}(t) & d_{C b}(t) \\
d_{A c}(t) & d_{B c}(t) & d_{C c}(t)
\end{array}\right]
$$

The Simulink implementation of duty cycle unit can be shown in Figure 11.

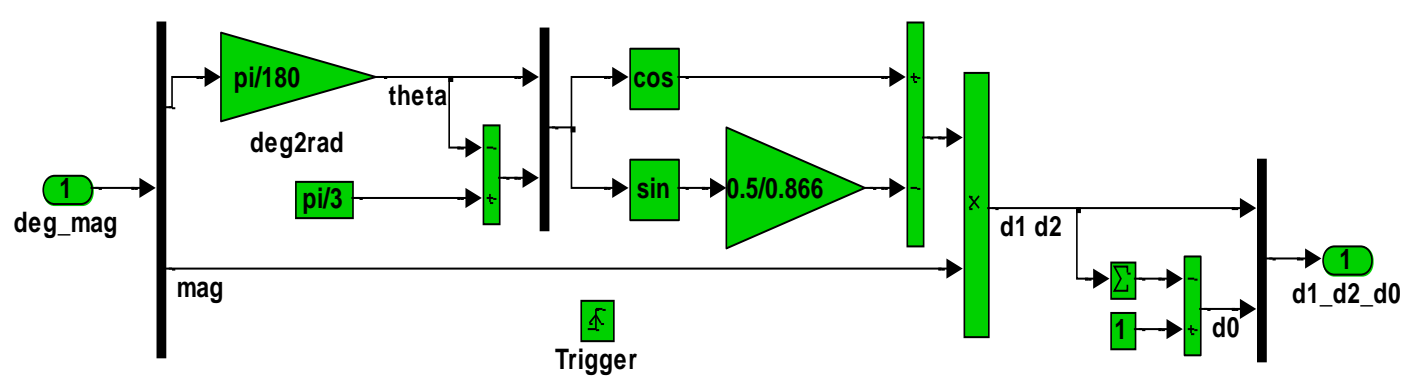

Figure 11. Simulink Implementation of Duty Cycle Calculation

$$
\begin{aligned}
& d_{1-} d_{2}=(\cos (\vartheta)-(\pi / 3-\vartheta) \sin (0.5 / 0.866))^{*}|v| \\
& d_{0}=1-\sum d_{1-} d_{2}
\end{aligned}
$$

The low-frequency component of the output phase voltage as in (14)

$$
V_{o p}(t)=D(t) \cdot V_{i / p}(t)
$$

The low frequency component of the input current as in (15)

$$
I_{i p}(t)=D^{T}(t) \cdot I_{o p}(t)
$$

The torque can be affected directly by the stator current as well as number of poles, mutual inductance and rotor inductance as in (16)

$$
T_{e}=p\left(L_{m} / L_{r}\right)\left(\psi_{d r} i_{q s}-\psi_{q r} i_{d s}\right)
$$

The SVM technique is one of the most important modulations used for the DMC due to the advantages of this technique like the reduction of total harmonic distortion and the controlling the duty cycle $100 \%$. The SVM rectifier system switching sequence can be implemented using two states current and voltage stages to yield the MC switching and hence the gates signals of the IGBTs of the MC as can be seen in the Figure 10.

The input current modulator and the voltage modulator are used for controlling of gates signals in efficient way. The DTC with MC proposed technique depends completely on the best choice of the switching mechanism to get better steady state error of both torque and flux compared to their references. The matric configuration switching technique used in this method can be illustrated in Table 2 .

Simulink implementation of hysteresis controllers of the torque and flux can be shown in Figure 12. 


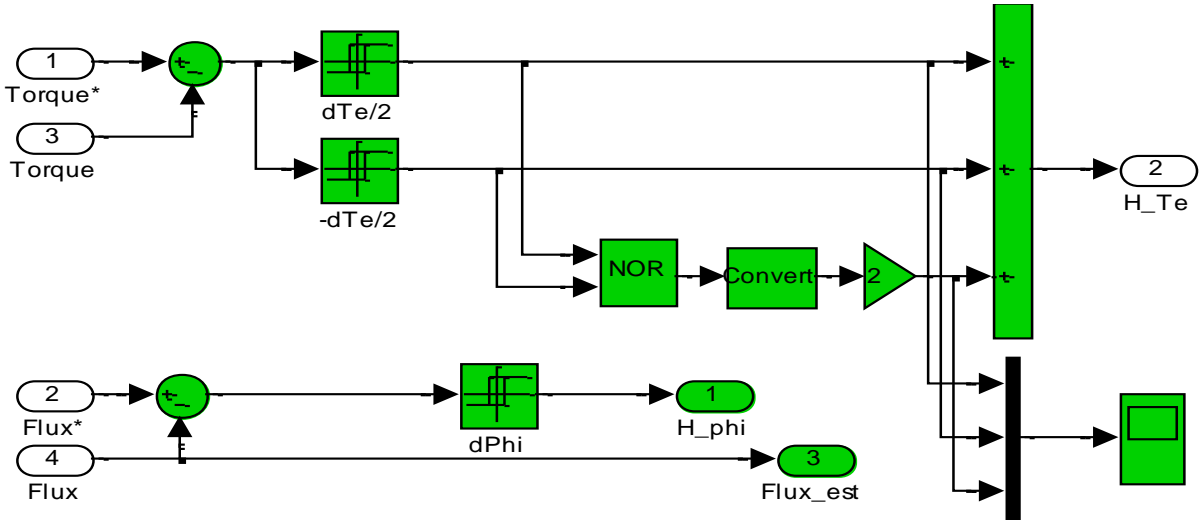

Figure 12. Simulink Implementation of the Torque and Flux Hysteresis Controllers

The Simulink implementation of voltage in alpha and beta coordinate can be shown in Figure 13.

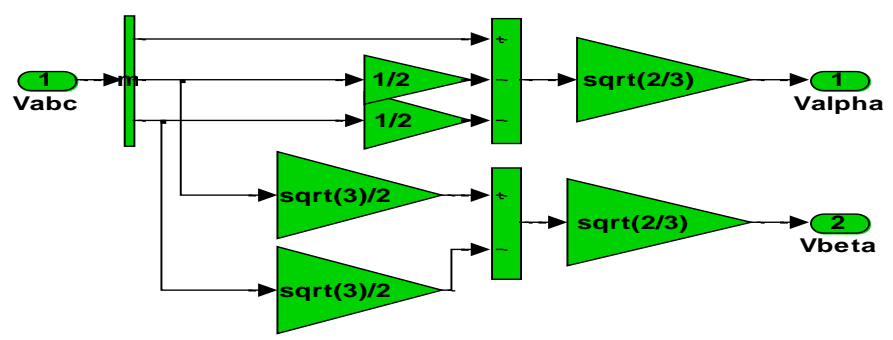

Figure 13. Simulink Implementation of Alpha \& Beta Voltage Components

\section{SIMULATION RESULTS}

To investigate the proposed algorithm, the Simulink program has been used first to model the IM, MC, DTC and speed controller. A nonlinearity compensation strategy has been developed to make better the speed control performance in all operation regions. The simulation has been carried out assuming that the sampling period is 20e-6 sec and ideal switching devices, $0.8 \mathrm{~Wb}$ flux reference. The results of the DTC control simulation are shown in the following figures. The MCDTC technique is simulated with Simulink to investigate the performance of the proposed control scheme.

Figure 14 shows the speed command and the speed tracking which is completely coincided when the speed command is changed from (0-650) RPM then increased and setteled with 1500 RPM.

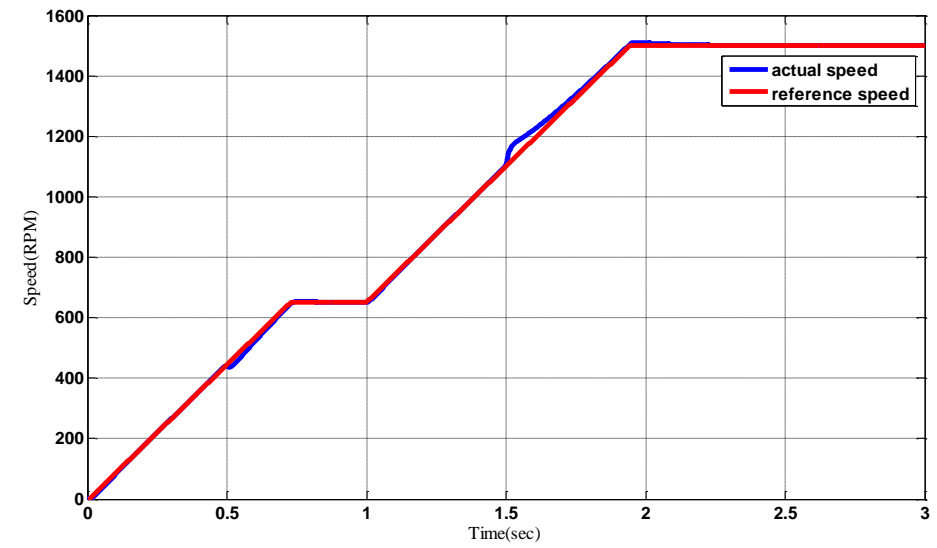

Figure 14. Speed Reference and Actual Speed Response 
The triangular reference torque compared to the actual torque to investigate the error that will be high frequency triangular waveform. Figure 15 shows the actual torque without constant switching frequency. The variable switching frequency in the basic DTC is due to the variation of the time taken for the torque error to achieve the upper and lower hysteresis bands. The dynamic performances of the proposed MCDTC control method are tested for a variable torque command. The waveform and the steady state error slopes are highly dependent on operating conditions. Consequently, the torque ripple will remain high, even with small hysteresis band.

The fluctuation in the DC voltage during the operation period can be shown in Figure 16. The torque ripples which are generated due to the operation of hysteresis controller are reduced by using the proposed control method as can be shown in Figure 17.

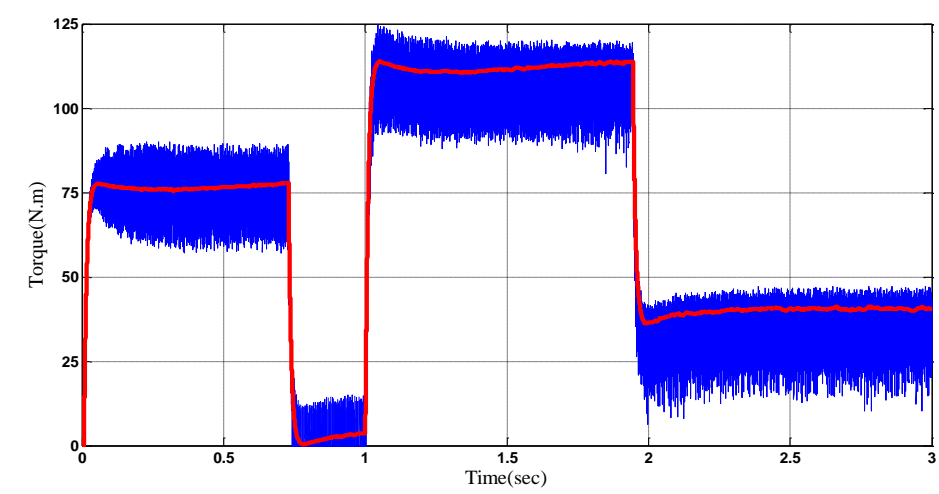

Figure 15. Actual (blue) and Reference Torque Dynamic without Constant Frequency DTC

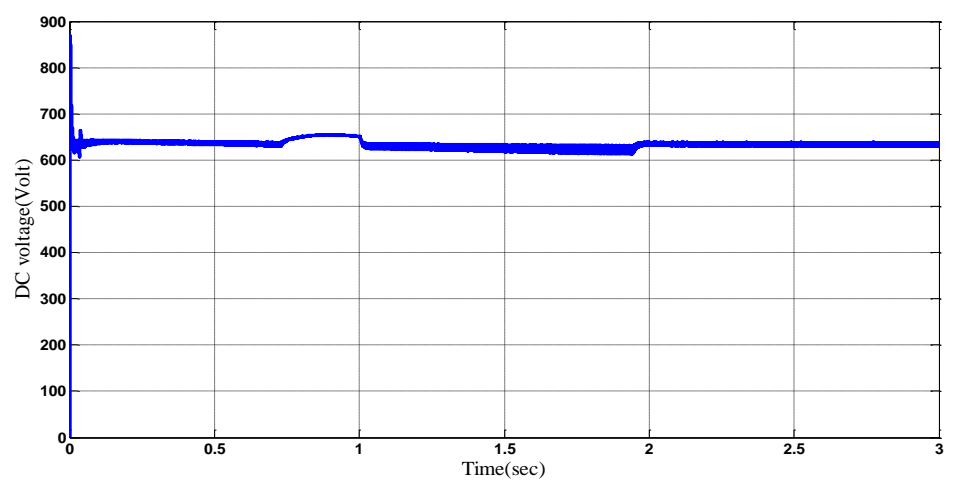

Figure 16. DC Voltage without Constant Frequency DTC

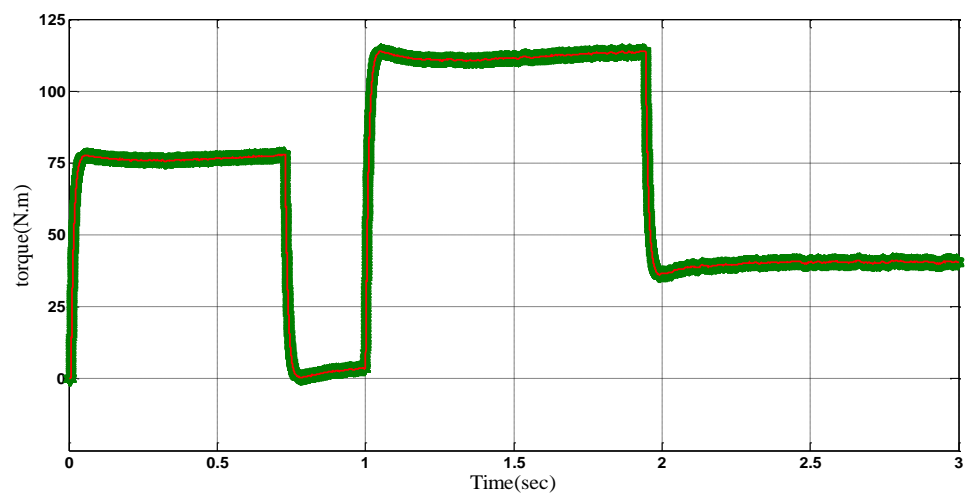

Figure 17. Actual and Reference Torques with Proposed DTC 
Stator current with proposed method can be shown in Figure 18.

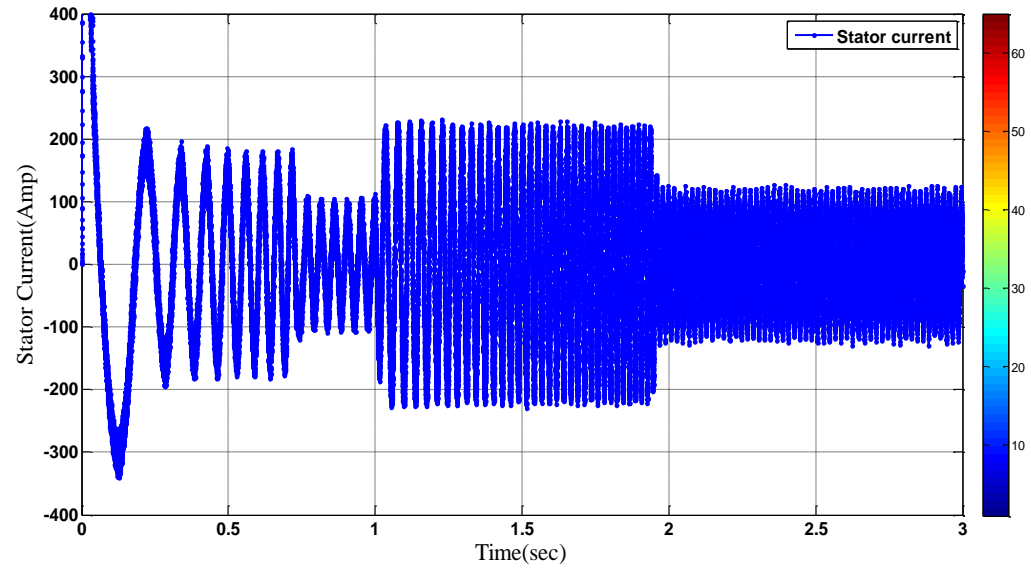

Figure 18. Stator Current with the Proposed DTC Scheme

The stator current in the Figure 18 shows acceptable results of the proposed strategy. The switching frequency of the IGBTs is $6 \mathrm{kHz}$ and can be realized up to $20 \mathrm{kHz}$.

To ensure better design of the proposed algorithm, 20 samples residues autocorrelation and cross correlation for both input and input combinations proves good results as can be shown in Figure 19.
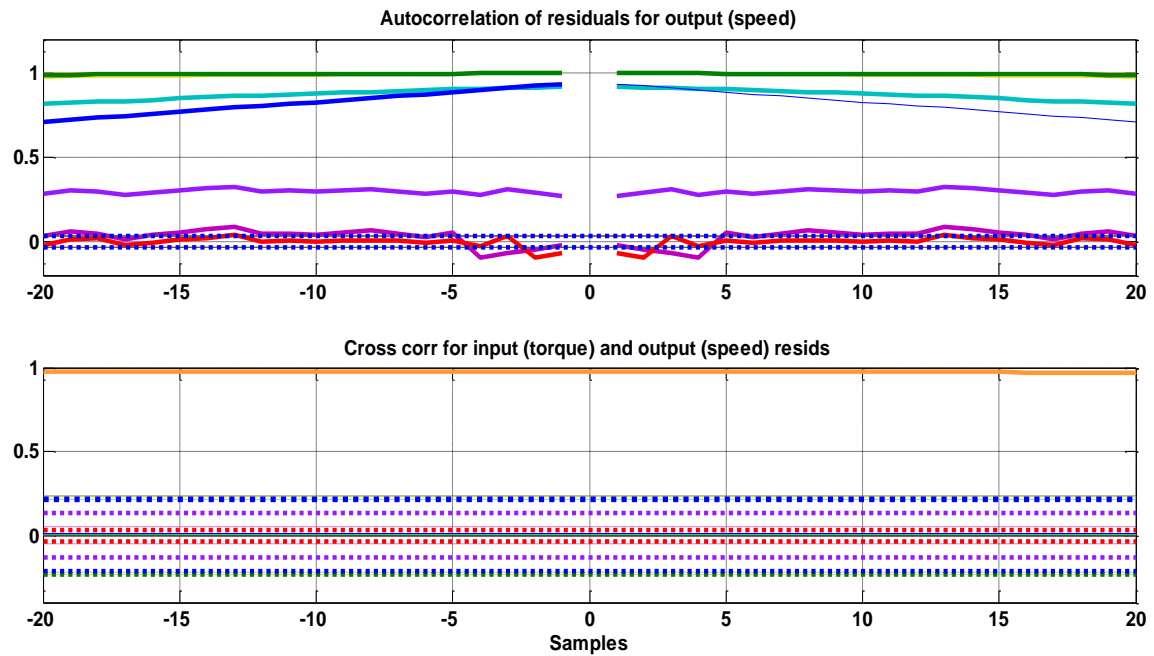

Figure 19. Autocorrelation and Cross Correlation Residuals

The transfer function of system from torque to the speed as in (17):

$G=\frac{0.00024 s^{-3}+2.744 e-6 s^{-2}+5.49 e-9 s+5.901 e-12}{s^{-4}+0.0055 s^{-3}+1.3 e-5 s^{-2}+2.74 s+2.34 e-11}$

The speed controller PI controller transfer function with zero delay time designed as in (18)

$G_{P I D}=\frac{K_{p}}{1+T_{p} s} * \exp \left(-T_{d} s\right), K_{p}=-0.233$,

$T_{d}=0, T_{p}=87.677$ 
The minimum difference between the input and the output has been tested through many fitting methods to ensure better performance in the IM as can be shown in Figure 20.

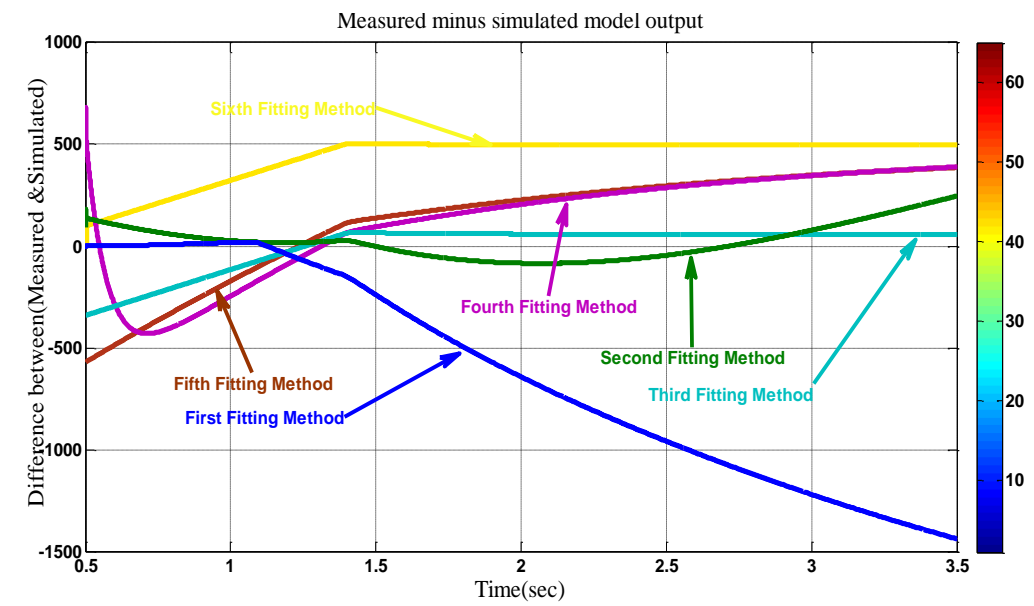

Figure 20. Nonlineary (blue) Test of the Output Regions

The values of of Figure 20 fitting method can be listed in the Table 3 using identification Matlab/Simulink toolboxes [29].

Table 3. Fitting Method to get the best Output Model

\begin{tabular}{ccc}
\hline The Fitting Method & The value & Name \\
\hline First Fitting method & -623.1 & Nlarx1 \\
SecondFitting method & 21.92 & N4s4 \\
Third Fitting method & 323.2 & N4s1 \\
Fourth Fitting method & -148.9 & arxqs \\
Fifth Fitting method & -148.8 & Arx441 \\
Sixth Fitting method & 0.194 & Nlarx2 \\
\hline
\end{tabular}

Nonlinear torque and speed harmful residual cross correlation can be shown in Figure 21 .
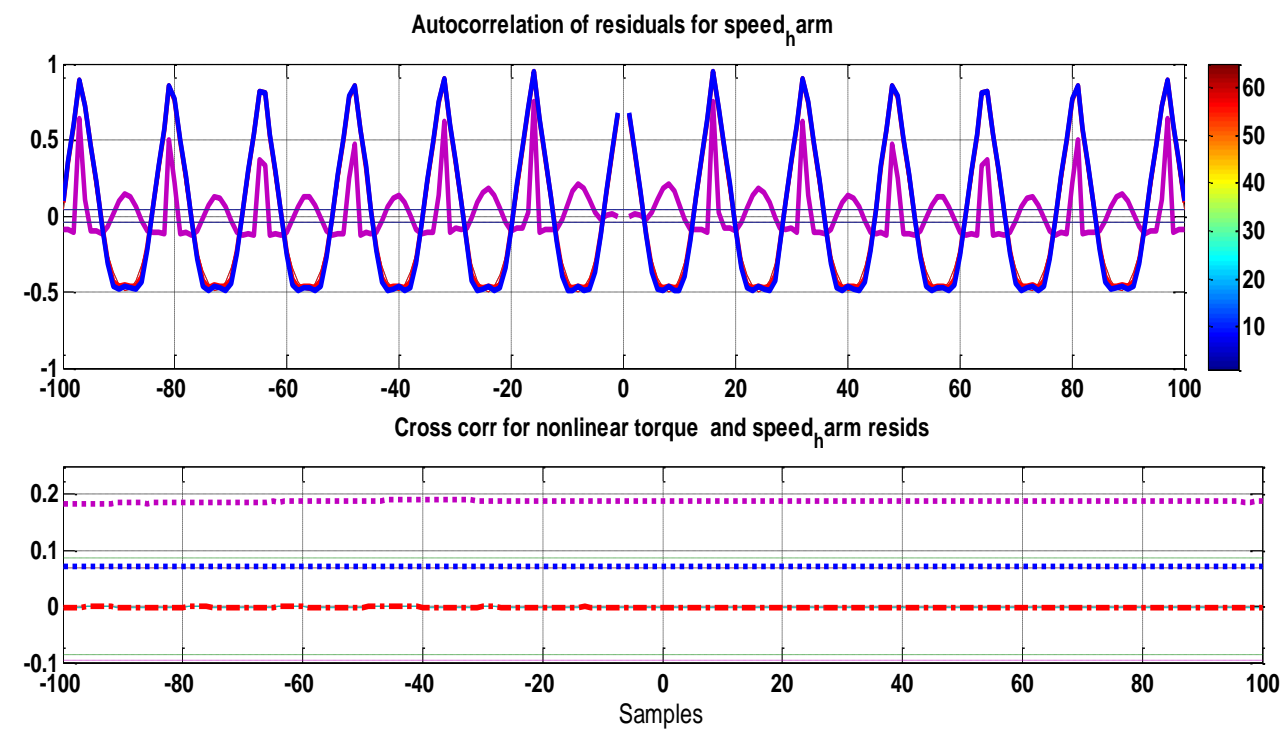

Figure 21. Nonlinear Torque and Speed Harmful Residual Cross Correlation 
Estimation of the nonlinearity of the output before and after applying the proposed algorithm will be listed in the Table 4.

Table 4. Nonlinearity Information with and without Proposed Algorithm

\begin{tabular}{cccccc}
\hline \multicolumn{2}{c}{ without constant switching Frequency } & \multicolumn{3}{c}{ With constant switching frequency } \\
Fit $(\%)$ & FPE & Loss Function & Fit $(\%)$ & FPE & Loss Function \\
\hline 90.21 & 1.303 & 1.086 & 99.9 & $1.918 \mathrm{E}-4$ & $1.872 \mathrm{E}-4$ \\
\hline
\end{tabular}

The state space model of the system will be 4th order, Matlab instruction is used to find whether the system is controllable, observable or not as in (19) \& (20).

$$
\begin{aligned}
C o & =\operatorname{cntrb}(A, B) \\
\mathrm{Co} & =\left[\begin{array}{llll}
0.0028 & -0.0676 & 0.1175 & -0.0507 \\
-0.2133 & 5.3307 & -7.4653 & -1.7762 \\
0.2165 & -5.4898 & 1.5892 & 3.8917 \\
-0.8181 & -0.0344 & 0.6350 & -0.8818
\end{array}\right] \\
O_{b s v} & =o b s v(A, C) \\
\mathrm{O}_{\mathrm{bsv}} & =\left[\begin{array}{cccc}
1.0 \mathrm{e}+03 * \\
1.6710 & -0.0439 & 0.0875 & -0.4993 \\
0.0000 & -0.0450 & -0.1128 & 0.9720 \\
-0.0004 & 0.1190 & -0.0226 & -0.4595 \\
-0.0000 & -0.0520 & 0.1766 & -0.8859
\end{array}\right]
\end{aligned}
$$

With rank of 4, the system is completely controllable and observable. The stability test determines if all roots of the input polynomial lie inside the unit circle. Implemented using the Schur-Cohn algorithm can be shown in Figure 22. The output is containing the value 1 or 0 . The value 1 indicates that the system is stable while the value 0 indicates that the system is unstable.

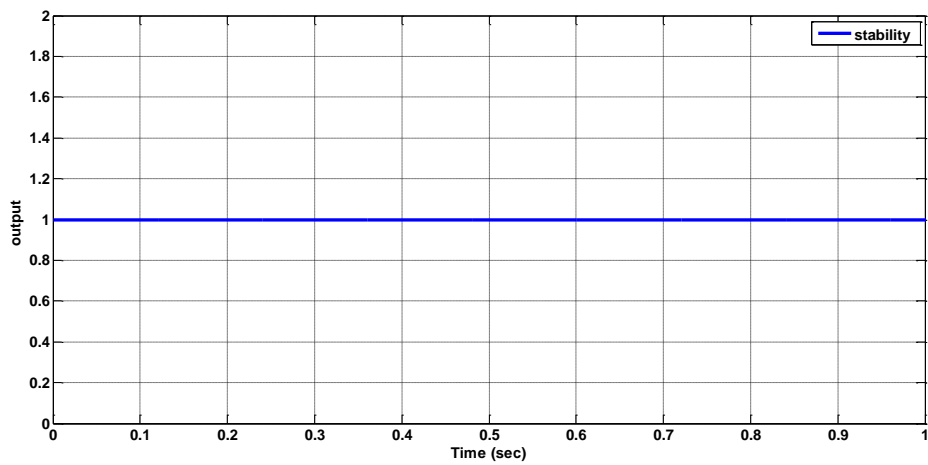

Figure 22. Stability Test according to Schur-Cohn Algorithm

\section{MODEL IMOROVMENT}

To insure best controller design, Estimation of Hammerstein-Wiener model before and after controller design can be used as can be shown in Table 5 and Table 6 . The block diagram represents the structure of a Hammerstein-Wiener model can be shown in Figure 23.

Because acts on the output port of the linear block, this function is called the output nonlinearity. If system contains several inputs and outputs, you must define the functions $\mathrm{f}$ and $\mathrm{h}$ for each input and output signal. 


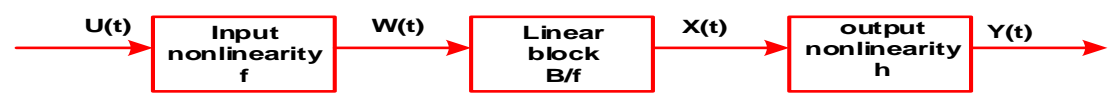

Figure 23. Block diagram of Hammerstein-Wiener

where: $w(t)=f(u(t))$ is a nonlinear function transforming input data $u(t)$. $w(t)$ has the same dimension as $\mathrm{u}(\mathrm{t}) \cdot \mathrm{x}(\mathrm{t})=(\mathrm{B} / \mathrm{F}) \mathrm{w}(\mathrm{t})$ is a linear transfer function. $\mathrm{x}(\mathrm{t})$ has the same dimension as $\mathrm{y}(\mathrm{t})$.

where $\mathrm{B}$ and $\mathrm{F}$ are similar to polynomials in the linear Output-Error model. For ny outputs and nu inputs, the linear block is a transfer function matrix containing entries:

$$
\text { linear Block }=B_{j, i}(q) / F_{j, i}(q)
$$

where $\mathrm{j}=1,2, \ldots$, ny and $\mathrm{i}=1,2, \ldots$, nu.

$y(t)=h(x(t))$ is a nonlinear function that maps the output of the linear block to the system output.

$\mathrm{w}(\mathrm{t})$ and $\mathrm{x}(\mathrm{t})$ are internal variables that define the input and output of the linear block, respectively. Because $\mathrm{f}$ acts on the input port of the linear block.

Table 5. Estimation of Hammerstein-Wiener model at the beginning

\begin{tabular}{ccccc}
\multicolumn{5}{c}{ at the beginning } \\
\hline 0 & $1.056 \mathrm{e}+04$ & Step size & Optimality & bisection \\
1 & $1 \mathrm{e}+04$ & 16.15 & $5.627 \mathrm{e}+04$ & 0 \\
2 & $1 \mathrm{e}+04$ & 2.201 & $5.595 \mathrm{e}+04$ & 9 \\
3 & 9983 & $7.226 \mathrm{e}-05$ & $3.276 \mathrm{e}+04$ & 6 \\
4 & 9982 & 1.763 & $3.329 \mathrm{e}+04$ & 8 \\
5 & 9982 & 1.102 & $3.492 \mathrm{e}+04$ & 9 \\
6 & 9979 & 43.82 & $3.328 \mathrm{e}+04$ & 5 \\
7 & 9978 & 4.269 & $1.704 \mathrm{e}+04$ & 6 \\
8 & 9977 & 1.174 & $1.986 \mathrm{e}+04$ & 8 \\
9 & 9976 & 1.137 & $2.031 \mathrm{e}+04$ & 8 \\
10 & 9975 & 0.795 & $2.031 \mathrm{e}+04$ & 8 \\
11 & 9973 & 1.51 & $2.041 \mathrm{e}+04$ & 7 \\
12 & 9972 & 0.7719 & $4.065 \mathrm{e}+04$ & 8 \\
13 & 9967 & 1.56 & $5.533 \mathrm{e}+04$ & 6 \\
14 & 9965 & 2.422 & $6.329 \mathrm{e}+04$ & 6 \\
15 & 9965 & 1.319 & $1.076 \mathrm{e}+05$ & 5 \\
16 & 9906 & 4.393 & $1.716 \mathrm{e}+04$ & 3 \\
17 & 9901 & 4.524 & $1.047 \mathrm{e}+05$ & 4 \\
18 & 9900 & 0.2971 & $1.046 \mathrm{e}+05$ & 8 \\
19 & 9757 & 0.3872 & $1.191 \mathrm{e}+04$ & 1 \\
20 & 9735 & 0.3884 & 8956 & 1 \\
\hline
\end{tabular}

Table 6. Estimation of Hammerstein-Wiener model after design the compensation

\begin{tabular}{ccccc}
\hline Itr & cost & $\begin{array}{c}\text { Step } \\
\text { size }\end{array}$ & Optimality & Bisection \\
\hline 0 & 2307 & & $2.037 \mathrm{e}+04$ & \\
1 & 1118 & 4.992 & $3.044 \mathrm{e}+05$ & 3 \\
2 & 785.6 & 25.44 & $1.315 \mathrm{e}+05$ & 2 \\
3 & 570.2 & 97.79 & $7.755 \mathrm{e}+04$ & 2 \\
4 & 306.1 & 64.22 & $1.695 \mathrm{e}+04$ & 2 \\
5 & 275.5 & 16.95 & $3.714 \mathrm{e}+04$ & 4 \\
6 & 264.4 & 2.193 & $6.382 \mathrm{e}+04$ & 5 \\
7 & 260.9 & 5.671 & $9.427 \mathrm{e}+04$ & 5 \\
8 & 257 & 1.376 & $1.01 \mathrm{e}+05$ & 6 \\
9 & 254.8 & 0.916 & $1.094 \mathrm{e}+05$ & 6 \\
10 & 254.1 & 1.219 & $1.206 \mathrm{e}+05$ & 6 \\
11 & 252.4 & 1.053 & $1.246 \mathrm{e}+05$ & 7 \\
12 & 251 & 0.5565 & $1.286 \mathrm{e}+05$ & 7 \\
13 & 249.8 & 0.5298 & $1.331 \mathrm{e}+05$ & 7 \\
14 & 248.8 & 3.35 & $1.379 \mathrm{e}+05$ & 7 \\
15 & 248 & 0.9778 & $1.42 \mathrm{e}+05$ & 7 \\
16 & 247.1 & 11.4 & $1.453 \mathrm{e}+05$ & 7 \\
17 & 246.5 & 4.16 & $1.493 \mathrm{e}+05$ & 7 \\
18 & 246 & 4.628 & $1.54 \mathrm{e}+05$ & 7 \\
19 & 245.6 & 1.2 & $1.58 \mathrm{e}+05$ & 7 \\
20 & 245.1 & 1.754 & $1.602 \mathrm{e}+05$ & 7 \\
\hline
\end{tabular}

The nonlinearity level in the circuit of IM can be shown as in Figure 24.
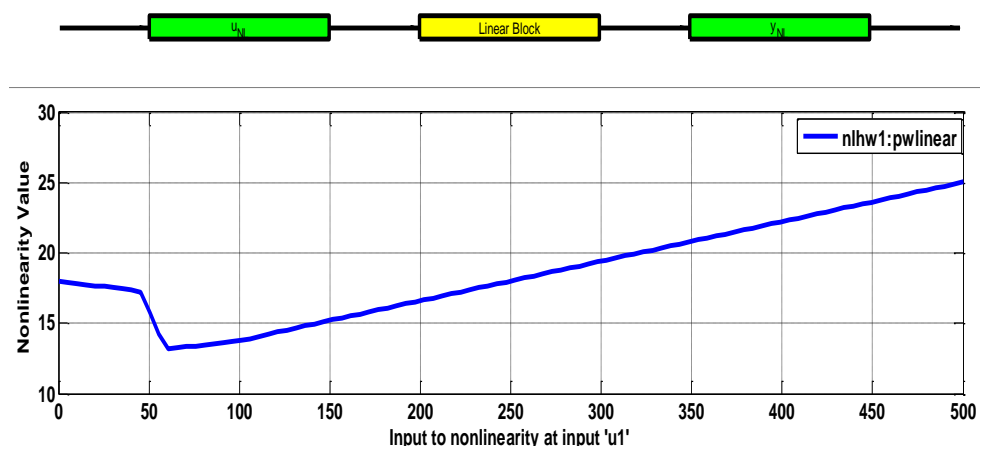

Figure 24. Nonlinearly Level after Design the Compensator 
The continuous canonical state space model of the given system will be as in the following form:

$$
\begin{aligned}
& X \cdot=A x+B u+K e \\
& y=C x+D u+e
\end{aligned}
$$

With the following values:

$$
\begin{aligned}
A & =\left[\begin{array}{lccc}
0 & 1 & 0 & 0 \\
0 & 0 & 1 & 0 \\
0 & 0 & 0 & 1 \\
2.7 e-5 & 0.028 & 1.05 & 0.166
\end{array}\right], B=\left[\begin{array}{l}
0.01 \\
4.8 e-5 \\
0.0008 \\
0.0001
\end{array}\right], C=\left[\begin{array}{llll}
1 & 0 & 0 & 0
\end{array}\right] \\
D & =[0], K=\left[\begin{array}{l}
0.55 \\
0.21 \\
0.12 \\
0.09
\end{array}\right]
\end{aligned}
$$

Another evidence to show the model improvement is the power distribution along with the operation of the system as shown in Figure 25.

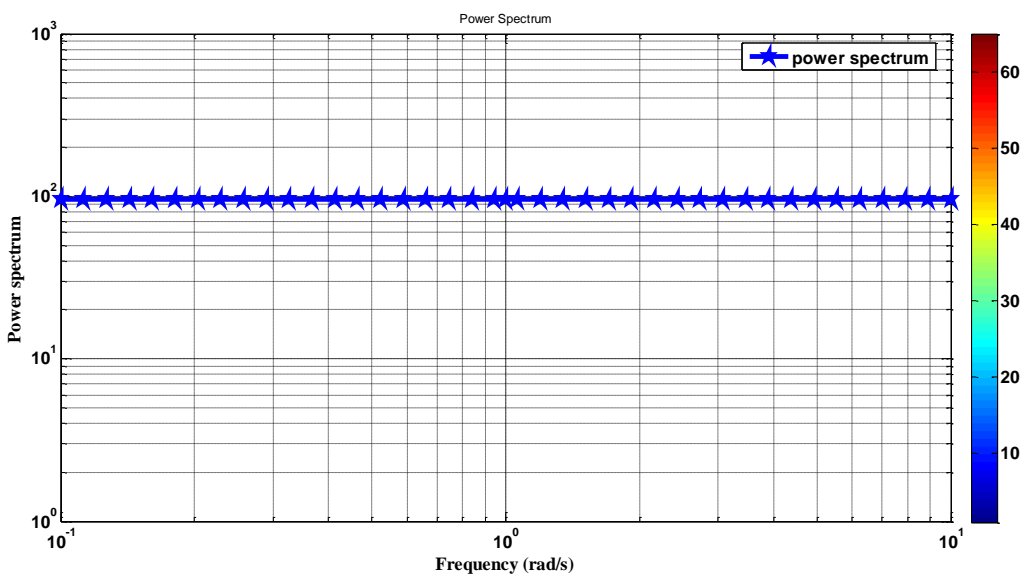

Figure 25. Power spectrum distribution

There are no sensitive parameters during the IM running with higher speeds, but at low speeds the stator flux estimation becomes so important and critical due to error in stator resistance property [30], [31].

\section{FAULT DIAGNOSIS}

The control of electrical machines, vehicle, space exploration faulty is very important in all industrial applications. The fault tolerant control princible are needed with these applications according to safety of operation of system operation. There are difference in operation and control between faulty and healthy machines. The danger of significant oscillations in faulted machine such as speed and torque oscillation is the main cause for damage of the machines [32]. The IM model is constructed with the following assumptions [33].

1. The air gap is of constant

2. No eccentricity effect,

3. The system works under balanced load,

4. Pure simusoidal input source. 
Shutting down the IM operation is another improvement especially when the motor performance is deteriorated. In Figure 26, both motor and the controller works presicely untle $0.6 \mathrm{sec}$ after that we simulate a fault between (0.6-1) sec to investigated the protection circuit which is reacts in a very good manner and stoped the operation to avoid the motor damage.

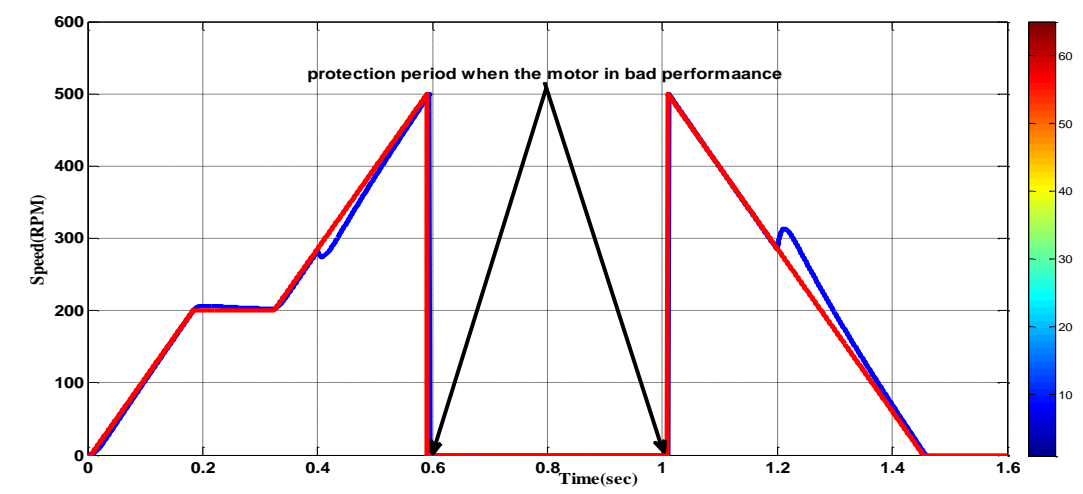

Figure 26. protection circuit activation

\section{CONCLUSIONS}

Hammerstein-Wiener is proposed as identified optimization model. DTC and MC modelling and simulation have been carried out. The proposed algorithm tested to ensure better performance specifications. DTCMC converter is used for supplying the IM. Minimizations of the steady state error of the torque with lowest final predicted error are obtained. Stability has been tested according to Schur-Cohn algorithm. The proposed algorithm with the constant switching frequency helped to design controllable, observable states of the given system. Protection circuit isn extra improvement for the proposed scheme which is not mentioned in detail in this paper. State space transfer function and design of the PI controller investigated with identification facilities of the Matlab/Simulink as well as the torque, the speed and current waveforms proves the effectiveness of the control scheme.

\section{REFERENCES}

[1] B. Sebti, et al., "Reduction of Torque Ripple in DTC for Induction Motor using in-put-output feedback linearizatio,” Turk J Elec Eng \& Comp Sci, vol/issue: 20(3), pp. 273-285, 2012.

[2] K. Gaeid, et al., "Sliding Mode Control of Induction Motor with Vector Control in Field Weakening," Modern Applied Science, vol/issue: 9(2), pp. 276-288, 2015.

[3] A. Aziz, et al., "A Simulation on Simulink AC4 model (200hp) DTC induction motor drive using Fuzzy Logic controller," Computer Applications and Industrial Electronics Conference, pp. 553-557, 2010.

[4] T. Noguchi and I. Takahashi, "Quick torque response control of an induction motor based on a new concept," IEEJ Tech. Meeting Rotating Mach, pp. 61-70, 1984.

[5] C. Reza, et al., "A review of reliable and energy efficient direct torque controlled induction motor drives," Renewable and Sustainable Energy Reviews, vol. 37, pp. 919-932, 2014.

[6] D. Casadei, et al., "The Use of Direct power converters in Direct Torque Control of Induction Machines," IEEE Trans. Industrial Electronics, vol/issue: 8(6), pp. 1057-1064, 2001.

[7] G. Buja and M. Kazmierkowski, "Direct torque control of PWM inverter-fed AC motors a survey," IEEE Transactions on Industrial Electronics, vol/issue: 51(4), pp. 744-757, 2004.

[8] T. Nabil, et al., "An Improved Fixed Switching Frequency Direct Torque Control of Induction Motor Drives Fed by Direct Matrix Converter," International Journal of Computer Science and Information Security, vol/issue: 7(3), pp. 198-206, 2010.

[9] S. Bhoopendra, et al., "Direct Torque Control Induction Motor Drive with Improved Flux Response," Advances in Power Electronics conference, pp. 1-11, 2012.

[10] R. Gupta, et al., "Direct Torque Control of Matrix Converter Fed Induction Motor Drive: A Review," Proc. of the Intl. Conf. on Advances in Computer, Electronics and Electrical Engineering, pp. 387-393, 2012.

[11] M. Kazmierkowski and G. S. Buja, "Direct Torque Control of PWM Inverter-Fed AC Motors A Survey," IEEE Trans.on Industrial Electronics, vol/issue: 51(4), pp. 744-758, 2004.

[12] A. Vanja, et al., "Band constrained technique for direct torque control of induction motor," IEEE Transactions on industrial Electronics, vol/issue: 51(4), pp. 776-784, 2004. 
[13] I. Kolar I., et al., "Novel three-phase ACDC- AC sparse direct power converter," Proceeding APEC, pp. 777-791, 2002.

[14] C. Klumpner, et al., "Control of a Two Stage Direct Power Converter with a Single Voltage Sensor Mounted in the Intermediary Circuit," 35th Annual IEEE PESC, pp. 2385-2392, 2004.

[15] K. Lee and F. Blaabjerg, "DTC-SVM for Induction Motor Driven by Matrix Converter Using a Parameter Estimation Strategy,” IEEE Trans. on Industrial Electronics, vol/issue: 55(2), pp. 512-521, 2008.

[16] K. Behera and S. Behera, "A Novel Control Strategy of Indirect Matrix Converter Using Space Vector Modulation," International Journal of Power Electronics and Drive Systems (IJPEDS), vol/issue: 7(3), 2016.

[17] N. Tha, et al., "Estimating Stability of MTDC Systems with Different Control," J Electrical Engineering Technology, vol/issue: 10(2), pp. 443-451, 2015.

[18] T. Friedli, et al., "Comparative Evaluation of Three-Phase AC-AC Matrix Converter and Voltage DC-Link Backto-Back Converter Systems," IEEE Transactions on Industrial Electronics, vol/issue: 59(12), pp. 4487-4510, 2012.

[19] Fourth gen DTC promises better speed and torque control at: http://www.drivesncontrols.com/news/fullstory, 2014.

[20] K. Vijayakumar, et al., "Application of Sinusoidal Pulse Width Modulation Based Matrix Converter as Revolutionized Power Electronic Converter," Power Electronics and Renewable Energy Systems, Springer India, 2015.

[21] K. Gaeid, "DTC Controller Design for IM with Wavelet Noise Reduction," European Journal of Scientific Research, vol/issue: 101(4), pp. 546-556, 2013.

[22] J. Kolar, et al., "Novel Three-Phase AC-AC Sparse Matrix Converters," Transactions of Power Electronics, vol/issue: 22(5), pp. 1649-1661, 2007.

[23] V. Patra, et al., "Integration of Matrix Converter with DTC of Induction Motor Drive Applications," International Journal of Advanced Research in Electrical, Electronics and Instrumentation Engineering, vol/issue: 2(10), pp. 5220-5231, 2013.

[24] D. Sharon, et al., "Three Phase to Three Phase Direct Matrix Converter using SPWM Technique," International Journal of Soft Computing and Engineering, vol/issue: 3(2), pp. 297-300, 2013.

[25] M. Abhijit and N. Manoj, "Performance Comparison of Matrix Converter fed Induction Motor Drive using PI and PID Control," Journal of Electrical and Electronics Engineering, vol/issue: 4(2), pp. 12-19, 2013.

[26] A. Alesina and M. Venturini, "Solid-state power con-version: a Fourier analysis approach to generalized transformer synthesis," Proc IEEE Trans Circuit System, vol. 28, pp. 319-330, 1981.

[27] L. Kyo and B. Frede, "Improved Direct Torque Control for Sensorless Matrix Converter Drives with Constant Switching Frequency and Torque Ripple Reduction," International Journal of Control, Automation, and Systems, vol/issue: 4(1), pp. 113-123, 2006.

[28] D. Abdelkader and M. Benyounes, "High Performance Motor Drive Using Matrix Converter," Acta Electrotechnica et Informatica, vol/issue: 2(7), pp. 1-8, 2007.

[29] www.mathwork.com/Matlab toolboxes.

[30] M. Kazmierkowski, et al., "High Performance Motor Drives," IEEE Industrial Electronics Magazine, vol/issue: 5(3), pp. 6-26, 2011.

[31] R. Adrian, et al., "Identification of Hammerstein-Wiener models," Automatica, vol/issue: 49(1), pp. 70-81, 2013.

[32] M. Jannati, et al., "A Novel Method for Vector Control of Faulty Three-Phase IM Drives Based on FOC Method," International Journal of Electrical and Computer Engineering (IJECE), vol/issue: 5(6), pp. 1284 1291, 2015.

[33] A. Chahmi, et al., "An Extender Kalman Filter-Based Induction Machines Faults Detection,” International Journal of Electrical and Computer Engineering (IJECE), vol/issue: 6(2), pp. 535-548, 2016.

\section{BIOGRAPHIES OF AUTHORS}

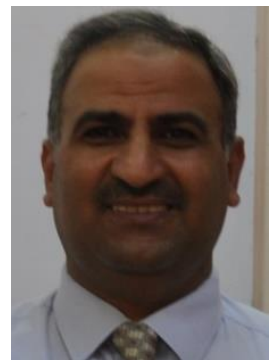

Khalaf S.Gaeid received the B.Sc. degree in electrical engineering/Control from MEC, Baghdad, Iraq in 1993 and the M.Sc. degree in Control Engineering from University of Technology, Baghdad, Iraq in 2004. He graduated from University of Malaya, Malaysia in 2012 with the $\mathrm{PhD}$ degree in control system and machine drives. His doctoral research was in the development new fault tolerant controller based wavelet for induction machines. He is currently assistant professor in control systems at the Department of Electrical Engineering, College of Engineering, Tikrit University, Tikrit, Iraq. His research interests include fault tolerant control, wavelet, fault diagnosis, machine drives and their applications in electrical engineering. He is IEEE member with a lot of publications in high rank journals and confrences. 


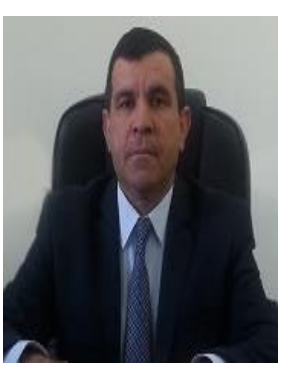

Ziad H. Salih was born in Kirkuk, Iraq in 1966. He received his Bachelor's (1989), Master's (1996) Degrees from University of Technology (Iraq) and $\mathrm{Ph}$. D. from the University of Technology (2008). He has been a lecturer of Control Theory I, II, Electronics and Electrical Networks at the Tikrit University, College of Engineering. He is the dean of the petroleum and mineral engineering college since 2014. Assistant prof. Dr. Ziad had achieved a lot of Journal articles and conference papers in the field of control and systems engineering. His current research and development interests are mainly in the following areas: PLC control, computer interfacing, self-tuning control and system identification, intelligent control, controller design for linear and non-linear systems, control design, industrial applications particularly in the oil industry.

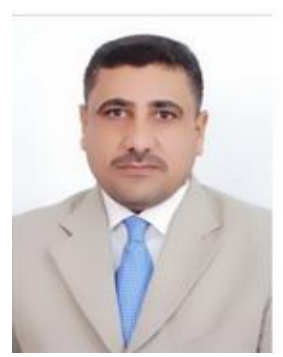

Mehdi J. Marie was born in Baghdad, Iraq in 1970. He received his Bachelor's (1993), Master's (2004) Degrees from University of Technology (Iraq) and Ph. D. from the University of Basrah (2014). He has been a lecturer of Control Theory I, II, Electronics and Electrical Networks at the Al-Nahrain University, College of Engineering. He is currently a senior engineer at Al-Zawaraa State Company, Ministry of Industry and Minerals (Iraq). Dr. Mehdi had achieved over seven Journal articles and two conference papers in the field of control and systems engineering. His current research and development interests are mainly in the following areas: self-tuning control and system identification, controller design for linear and non-linear systems, industrial applications particularly in the processing industry (for example refining, cement, plastic and food industry).

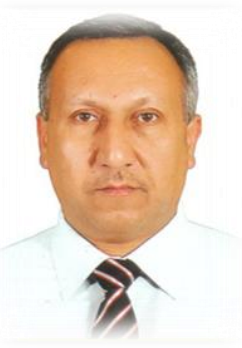

Ahmed R. Ajel, has been a full-time lecturer in the Institute of Technology Baghdad/Iraq, Ministry of higher education and scientific research/Iraq. Received his BSc. (1992), MSc. In control engineering, (1996) and PhD Degree in Electrical and Electronics engineering from the University of Technology (2006), Baghdad/Iraq, Head of Information and Communication Technology in Institute of Technology Baghdad/Iraq from 2012-2015, and head of the Consulting \& the Scientific Bureau in Institute of Technology Baghdad/Iraq from 2016 to yet. 